Copyright (C) 2021 by Cherkas Global University

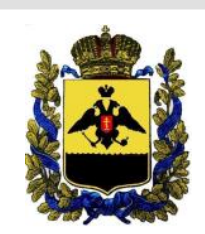

Published in the USA

Bylye Gody

Has been issued since 2006.

E-ISSN: $2310-0028$

2021. 16(4): 2005-2013

DOI: $10.13187 /$ bg.2021.4.2005

Journal homepage:

https://bg.cherkasgu.press

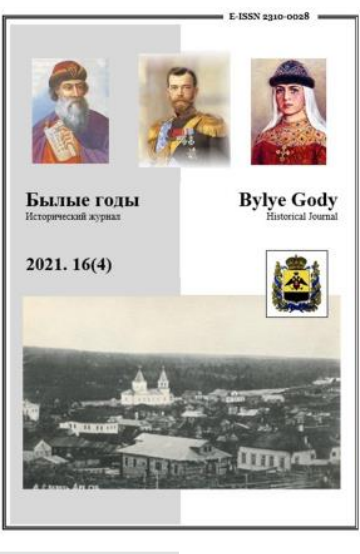

\title{
Evolution of the Views of Russian Monarchists on Ensuring Political Stability in the period $1905-1917$
}

\author{
Stanislav E. Prokofiev a, Pavel S. Seleznev a , *, Aleksey V. Fedyakin b, Viktor V. Titov a \\ ${ }^{a}$ Financial University under the Government of the Russian Federation, Moscow, Russian Federation \\ ${ }^{b}$ Russian University of Transport, Russian Federation
}

\begin{abstract}
This work is devoted to the topic of changing the views of Russian monarchists on the strategy of ensuring the stability of the political and social regime of the empire in the period 1905-1917. The aim of the study is to identify the main vectors and trends in the evolution of the views of monarchists on the strategy of ensuring political stability in the Russian Empire in the designated chronological period. The source base of the work is formed by attracting materials from the pre-revolutionary periodicals, sources of personal origin and publications of office documents and program materials of political parties. The methodology of the work is built on the basis of a combination of synchronous and diachronic comparative analysis. It is concluded that during the period under review, the views of monarchists on the strategy of ensuring the political stability of the empire were actively evolving. Initially, they did not have their own views on this issue, delegating the function of determining the vector of its decision to the system of the current government. However, as the revolutionary crisis grew, the monarchists began to develop their own position on this issue. Initially, popular were the ideas of a partial limitation of the powers of the recently created parliamentary institutions or the restoration of "primordially autocratic principles" in the system of state administration. However, in the end, the point of view of moderate monarchists prevailed, insisting on the need to create mechanisms to cut off political radicals from participation in legislative activity. In the period 1907-1911 the monarchists promoted the idea of the need to combine moderate reforms with the conservation of social institutions that ensure the functioning of the patriarchal model of Russian society. At the same time, attention was focused on the fact that transformations in the socio-economic sphere should become a priority for the authorities: the transition to political reforms in the absence of an increase in living standards was seen as fraught with the beginning of new revolutionary uprisings. In the future, the monarchists moved to more radical positions. They proposed to rebuild the political and economic models of the organization of society in the spirit of corporatism. During the First World War, they actively discussed projects for the establishment of the post of a dictator, uniting in his hands the supreme powers in the civil and military spheres. Thus, the monarchists went beyond the traditionalist paradigm of autocracy. At the same time, their very perception of political stability was transformed. Initially it was seen as a static state corresponding to the "sacred past". However, by the end of the period under study, monarchists perceived stability as a state of the political system that allows political and social systems to remain resistant to external and internal challenges through evolutionary transformations or the creation of new extraordinary institutions and forms of management or economic organization.
\end{abstract}

Keywords: monarchists, conservatives, socio-political thought, political stability, Russian Empire, revolution.

\footnotetext{
${ }^{*}$ Corresponding author

E-mail addresses: SEProkofev@fa.ru (S.E. Prokofiev), PSeleznev@fa.ru (P.S. Seleznev), avf2010@yandex.ru (A.V. Fedyakin), VVTitov@fa.ru (V.V. Titov)
} 


\section{1. Введение}

Долгое время дореволюционные монархические организации стигматизировались в научной литературе как «черносотенные», что закономерно негативным образом отразилось на описании и анализе политических воззрений их представителей. В постсоветский период была произведена ревизия политического наследия дореволюционных монархистов. Однако его изучение также зачастую проходило на не вполне объективных основаниях. Взгляды и оценки монархистов интерпретировались с позиций постзнания. На них существенное влияние оказывало и длительное господство либерального дискурса в исторической публицистике в период 1990-х гг., а также попытки описания политических воззрений монархистов в преимущественно философском или религиозном ключе, в отрыве от исторического контекста и политической конъюнктуры.

В результате были сформированы мемориальные рамки, обусловившие восприятие политических воззрений дореволюционных монархистов в ракурсе упрощения их реальной позиции. Последнее проявляется в том числе в крайней степени обобщения их взглядов и фактическом отрицании их эволюции под влиянием динамики внешне- и внутриполитической ситуации. Следствием этого стало появление объяснительных моделей, в рамках которых поведение монархистов на политической арене дореволюционной России описывалось и оценивалось скорее с позиции априори недостоверных стереотипов.

На этом фоне объективная переоценка политических воззрений дореволюционных монархистов представляется важным условием обеспечения сообщества профессиональных историков релевантной эмпирической базой в рамках концептуализации процесса гибели Российской империи. И в первую очередь это касается восприятия монархистами способов обеспечения внутриполитической стабильности, поскольку именно эта задача выступала в их глазах стратегическим приоритетом с начала периода революционных потрясений в 1905 г.

Целью представленного исследования является оценка эволюции взглядов монархистов на стратегию обеспечения политической стабильности в Российской империи в период 1905-1917 гг.

\section{2. Материалы и методы}

Источниковая база исследования включает в себя материалы дореволюционной периодической печати (публикации в таких изданиях, как «Голос долга», «Мирный труд» и «За Россию»), источники личного происхождения (Богданович, 1990; Головин, 2006; Гурко, 2000; Кизеветтер, 2001) и публикации делопроизводственных документов и программных материалов политических партий (Падение царского режима, 1924; Программы политических партий, 1995; Устав и Основоположения, 1906).

Методология работы выстраивается на основе сочетания синхронного и диахронного сравнительного анализа. Использование первой методики позволяет сопоставить между собой взгляды различных групп монархистов в одно и то же время, применение второй - проследить эволюцию воззрений сторонников монархии на протяжении исследуемого периода.

\section{3. Обсуждение}

В рамках дореволюционной историографии тема изучалась преимущественно косвенным образом, в контексте вопроса об участии партий в работе Государственной Думы первых созывов (Винавер, 1907; Езерский, 1907; Львович, 1906; Мышцин, 1906).

В публикациях советского периода исследователи освещали политические воззрения монархистов как самостоятельный предмет изучения. Однако вместо объективного анализа эмпирического материала они были вынуждены скорее заниматься подбором фактов под заранее сформулированные идеологические положения (Волобуев и др., 1989; Комин, 1965; Спирин, 1968; Спирин, 1977).

В постсоветский период возникла возможность изучения заявленной темы на основе принципа объективности. Однако она исследовалась преимущественно либо в контексте более широких по объему вопросов, либо в ключе разработки ее отдельных аспектов (Боханов, 2006; Вортман, 1999; Кирьяков, 2001; Курицын, 2018; Омельянчук, 2020). Результатом этого является лакунарный характер степени научной разработанности заявленной темы.

\section{4. Результаты}

Непосредственному обращению к вопросу о восприятии условий обеспечения политической стабильности представителями монархических партий и движений должен предшествовать анализ соответствующего концепта.

И в зарубежной, и в российской науке исследователями было выработано множество вариантов интерпретации понятия «политическая стабильность».

А.С. Макарычев выделил в работах зарубежных экспертов пять подходов к определению обозначенного термина.

Согласно первому из них, политическая стабильность представляет собой состояние общественно-политической системы, для которого характерно отсутствие каких-либо угроз, 
связанных с масштабным распространением нелегитимного насилия, или наличие у властных институтов возможности легко устранить либо купировать подобные риски (Ф. Били, Д. Яворски).

В рамках второго подхода стабильность рассматривается как сочетание сохранения конституционного строя с преемственностью политического курса (С. Хантингтон).

Сторонники третьего подхода определяют политическую стабильность как производную высокой легитимности власти (Д. Заллер, С. Липсет, Д. Истон).

Представители четвертого подхода позиционируют политическую стабильность как отсутствие значимых изменений в политической структуре или наличие механизмов управления данными трансформациями со стороны истеблишмента (Т. Парсонс).

Пятый подход основывается на толковании стабильности как социально-политического состояния, в рамках которого представители конкретного сообщества с высокой долей последовательности и жесткости ограничивают свое поведение социально приемлемыми нормами (Г. Гортц) (Макарычев, 1998: 151-153; Хантингтон, 2004: 75).

В зарубежной науке также был выработан ряд оригинальных вариаций интерпретации политической стабильности. В частности, К. Даудинг и Р. Кимбер описывают стабильность как состояние политической системы, в рамках которого она способна успешно купировать внешние и внутренние угрозы. Т. Парсонс позиционировал стабильность как состояние, в рамках которого внутренние связи между элементами политической системы сильнее внешних контактов (Doweling, Kimber, 1983: 32-33).

Обобщение описанных выше подходов позволяет выделить такие сущностные характеристики политической стабильности, как наличие релевантных механизмов разрешения внутренних противоречий и устранения внешних угроз, структурная устойчивость институтов управления и инструментов поддержания легитимности существующего политического режима.

Для российской науки также характерно отсутствие конвенционального определения понятия «политическая стабильность».

М.Г. Анохин интерпретирует его как состояние политической системы, которому присущи устойчивость, структурная целостность и способность системы управления успешно функционировать под давлением со стороны внешних и внутренних акторов (Гришин, 2015: 51).

А.И. Соловьев рассматривает политическую стабильность как состояние баланса в сфере и внутри- и внешнеполитических отношений государства, обеспечивающее генерацию потенциала эксплуатации политических механизмов для решения задач сохранения и развития властных институтов и заданной ими социальной системы (Гришин, 2015: 51-52).

М.А. Василик описывает политическую стабильность как состояние социальной устойчивости, формирующее потенциал эффективного функционирования и развития общества в условиях коммуникации с внешними и внутренними акторами, а также позволяющее сохранить его структуру и институты, отвечающие за определение вектора процесса социальных трансформаций (Гришин, 2015: 52).

В.Н. Иванов определяет политическую стабильность как способность политической системы длительное время функционировать в отсутствии резких перемен (Гришин, 2015: 52).

С.И. Бойко оценивает политическую стабильность как состояние политического режима, для которого характерны динамичность, устойчивость, непрерывность в плане основных характеристик и эволюционная модель развития. В рамках данного состояния трансформация политического процесса осуществляется без использования инструментов актуального насилия. Последнее обеспечивает, с одной стороны, наличие адекватной формы конверсии власти в рамках цепочки «государство - общество - государство», а с другой - сбалансированный характер отношений как между группами истеблишмента, так и между элитой и прочими макросоциальными группами. В качестве дополнительных условий поддержания политической стабильности исследователь выделяет наличие «политического равновесия» между основными акторами и «цивилизованных» форм выстраивания диалога между ними (Гришин, 2015: 52-53).

Соответственно, российской научной традиции присуща тенденция расширенного истолкования понятия «политическая стабильность» за счет включения в его объем функции регулирования социальных трансформаций, а также четкая взаимосвязь понятий «политическая стабильность» и «устойчивое развитие». Фактически под состоянием политической стабильности так или иначе подразумевают комплекс факторов, обеспечивающих устойчивое развитие конкретной социально-политической системы, а не просто совокупности взаимосвязанных властных институтов.

Российские исследователи заостряют внимание на решении таких задач, как сохранение структурной целостности политической системы и обеспечение способности эффективно реагировать на внешние и внутренние вызовы. За счет этого функциональное описание политической стабильности в российской и зарубежной научной традициях совпадают, за исключением элемента легитимности, выделяемого западными политологами.

В целом можно заключить, что политическая стабильность представляет собой состояние политической системы, в рамках которого она способна длительное время сохранять структурную 
устойчивость, в то же время релевантно реагируя на внешние и внутренние угрозы, адаптируясь к ним без изменений своих фундаментальных характеристик.

Таким образом, стабильность и преобразования не являются взаимоисключающими понятиями. Они, напротив, тесно взаимосвязаны: наличие хотя бы минимального уровня стабильности политической системы является значимой гарантией ее успешного реформирования. Стабильность - парадигмальное свойство поступательного развития. И в то же время принципиальным условием поддержания стабильности любой системы можно назвать изменчивость ее подсистем, их способность к постепенному накоплению новых элементов на пути трансформации при сохранении базовых параметров.

Первоначально у многих организаций монархического толка не было полноценных и четко сформулированных представлений о способах обеспечения политической стабильности в империи. Показательно в этом плане программное воззвание «Союза русских людей». Стратегия данного объединения на политической арене определялась следующим образом: «стараться правильно выполнить царскую волю и без корысти выбирать по первому государеву призыву истинно достойных людей». Таким образом, первоначально многие монархисты отказывали себе в полноценной субъектности и намеревались выступать лишь в качестве проводника воли императора (Программы политических партий, 1995: 79).

Однако эта установка достаточно быстро начала вытесняться различными вариантами более активной политической позиции. В крайне правых кругах была выработана установка на возвращение к модели самодержавной власти дореволюционного образца («в том неприкосновенном виде, в котором Государь получил ее от своих Царственных предков»). При этом важно подчеркнуть, что это не подразумевало полной отмены «Манифеста 17 октября». Сторонники данной позиции настаивали на необходимости придать как Государственному Совету, так и Государственной Думе законосовещательный характер. Дума в рамках такой конструкции должна была представлять собой инструмент обеспечения прямой связи между монархом и широкими слоями населения, направляющими императору свои просьбы через депутатов в обход высшей бюрократии и ведомственной вертикали. Также предполагалось сохранить за наемными рабочими права на создание профсоюзов, но одновременно запретить для подданных вступление в политические объединения (например, на этом настаивали представители Отечественного союза) (Богданович, 1990: 49; Винавер, 1907: 35; Устав и Основоположения, 1906: 12; Головин, 2006: 15).

Интересно отметить, что представители данного подхода не нашли поддержки среди высшего политического руководства империи по причине именно излишней (с точки зрения действующей власти) субъектности. Так, описанный подход активно продвигали монархические круги, группировавшиеся вокруг издания «Московские ведомости». Однако в своей риторике они дошли до косвенной критики императора, настаивая на том, что монарх не имел права ограничивать права самодержца, переданные ему предками. Последнее закономерно спровоцировало вспышку раздражения среди высшего политического руководства. Подобные заявления были расценены как попытка «взять опеку» над монархом (Гурко, 2000: 57$)$.

Вместе с тем многие умеренные монархисты из числа лидеров общественного мнения (к их числу относились, например, В.И. Гурко, А.А. Киреев и А.С. Суворин) пришли к осознанию необратимости политической реформы 1905 г. В.М. Пуришкевич и вовсе полагал, что Государственная Дума могла стать полноценным парламентом, однако этому препятствовало низкое правосознание населения. При этом умеренные монархисты (в частности, А.А. Киреев) настаивали на необходимости переформатирования парламентского механизма в ключе, позволяющем отсечь от законодательной деятельности неготовых идти на компромиссы с монархией политиков правого и левого толка. Фактически речь шла о реформе Государственной Думы по сценарию, впоследствии реализованному властями в рамках режима «третьеиюньской монархии» (Гурко, 2000: 61; Киреев, 1907: 225; Курицын, 2018: 87; Пуришкевич, 1907: 15).

Умеренные монархисты признавали, что в России активно развиваются те же социальноэкономические процессы, что и в Западной Европе в XVIII-XIX вв. (в качестве примера можно привести работы А. Швецова и А. Доброхотова). Однако сопутствующие изменения, по мнению умеренных монархистов, вызывали отторжение у основной массы населения. Равным образом российские монархисты отстаивали необходимость сохранения системы сословного деления и разработки мер государственной опеки в отношении конкретных социальных групп - духовенства, дворянства и крестьянства, которые рассматривались в качестве главных носителей национальной модели социально-политического устройства. В то же время декларировалась необходимость экстренной разработки либо усовершенствования крестьянского и рабочего законодательства. Последнее объяснялось тем, что, по мнению большинства мыслителей из числа умеренных монархистов, проведению даже умеренных либеральных преобразований в обязательном порядке должно предшествовать повышение уровня жизни широких масс населения. В противном случае распространение капиталистических отношений и соответствующих форм организации политической власти неизбежно будет провоцировать революционные выступления (Архиепископ Никанор, 1912: 5; Берман, 1913: 1912; Вараксин, 1912: 20; Доброхотов, 1907: 67; Швецов, 1907: 61). 
Отдельно необходимо отметить наличие такого направления в монархической публицистике, как критика коррумпированности государственного аппарата. По мнению многих сторонников монархии, коррупция представляла собой почти такую же опасность для стабильности существуюего строя, как и действия политических радикалов из левого и либерального лагеря. Неслучайно накануне открытия заседаний III Государственной Думы М.О. Меньшиков в своей речи заострил внимание на том, что именно коррупция, произвол и равнодушие властей входят в число основных факторов, провоцирующих начало «кровавых бунтов» (Омельянчук, 2020: 434).

Тема борьбы с коррупцией достаточно органично сплелась в монархической публицистике с традиционными взглядами на роль императора в системе управления. Монарх, обладающий правом отменить любое решение суда или даже закон в случае наличия опасности для общества, позиционировался как главный фактор, ограничивающий эгоизм элит и вынуждающий их выполнять функцию «служения общему благу» (Ухтубужский, 1912: 14).

Именно эта система представлений стала парадигмальным элементом позднейших воззрений монархистов на механизмы обеспечения внутриполитической стабильности империи.

После смерти П.А. Столыпина и начала постепенного свертывания инициированной им программы реформ монархисты, с одной стороны, начали выражать все больше симпатий идеям корпоративизма. В наиболее радикальных формах они сводились к национализации всех «источников труда» и фактическому превращению всех подданных в государственных служащих (Голос долга, 1912: 6; Кизеветтер, 2001: 112; Ухтубужский, 1912: 14).

С другой стороны, уже в период Первой мировой войны в монархической печати все чаще стали публиковать материалы, авторы которых настаивали на создании поста временного диктатора, который объединил бы в своих руках высшую гражданскую и военную власть. Интересно отметить, что впоследствии бывший председатель совета министров Б.В. Штюрмер сообщил членам чрезвычайной следственной комиссии Временного правительства, что в 1916 г. высшее политическое руководство империи действительно обсуждало возможность соответствующего шага.

Однако среди монархистов отсутствовал консенсус относительно того, на кого можно было бы возложить полномочия диктатора. Император уже являлся Верховным главнокомандующим, однако «великое отступление» 1915 г. и неудачи войск Западного фронта в 1916 г. заметно подорвали его авторитет в данном качестве. В то же время вручение этих полномочий другому лицу порождало в перспективе угрозу государственного переворота (За Россию, 1916; Падение царского режима, 1924).

\section{5. Заключение}

Таким образом, взгляды российских монархистов на стратегию стабилизации политической ситуации в России в течение рассматриваемого периода претерпели значительную эволюцию. Первоначально у них не было собственных программных воззрений по данному вопросу, определение вектора его решения они целиком доверили действующей власти. Однако по мере разрастания революционного кризиса монархисты были вынуждены выработать собственную позицию по данному вопросу. Первоначально широкой популярностью пользовались идеи частичного ограничения полномочий недавно созданных парламентских институтов или даже полного возвращения к «исконно самодержавным началам». Однако данная позиция соседствовала с критикой действий политического руководства империи, что вызвало резкую реакцию с его стороны. В итоге возобладала точка зрения умеренных монархистов, настаивавших на необходимости блокирования участия политических радикалов в законодательной деятельности. Фактически ими был предложен (в концептуальном виде) политический курс, ставший основой для конструирования режима «третьеиюньской монархии».

В период 1907-1911 гг. монархисты продвигали в рамках публичного дискурса тезис о необходимости сочетать умеренные реформы с консервацией социальных институтов, обеспечивающих функционирование патриархальной модели российского общества. При этом подчеркивалось, что приоритетом обладают преобразования в социально-экономической сфере: переход к политическим реформам в отсутствии роста уровня жизни рассматривался как чреватый началом новых революционных выступлений.

Рост социального недовольства и реанимация рабочего движения, наряду со свертыванием программы реформ П.А. Столыпина, подтолкнули монархистов к формулированию более радикальных способов обеспечения политической стабильности, вплоть до проведения корпоративистских реформ. Первая мировая война и вовсе поставила на повестку дня вопрос о создании должности диктатора, объединяющего в своих руках верховные полномочия в гражданской и военной сферах. За счет этого монархисты фактически вышли за пределы традиционалистской парадигмы самодержавия и перешли на идеологическое поле европейских правых. При этом трансформировалось и само восприятие политической стабильности. Если первоначально она рассматривалось как статичное состояние, соответствующее «священному прошлому», то в последующем монархисты воспринимали ее уже как состояние политической системы, позволяющее обществу сохранять устойчивость к нарастающим внешним и внутренним вызовам за счет эволюционных преобразований или создания новых экстраординарных институтов и форм 
управления. За счет этого монархисты фактически ушли от профанного понимания стабильности как отсутствия изменений и приблизились к ее научной трактовке.

\section{6. Благодарности}

Статья подготовлена по результатам исследований, выполненных за счет бюджетных средств по государственному заданию Финансовому университету при Правительстве Российской Федерации.

\section{Литература}

Архиепископ Никанор, 1912 - Архиепископ Никанор. О верноподданнических обязанностях // Голос долга. 1912. № 5. С. 4-11.

Берман, 1913 - Берман Я. Влияние социально-правового и экономического фактора на государственную преступность // Право. 1913. № 33. С. 1912-1914.

Богданович, 1990 - Богданович А.В. Три последних самодержца. Дневник. М., 1990.

Боханов, 2006 - Боханов А.Н. Последний царь. М., 2006.

Вараксин, 1912 - Вараксин А. Царское самодержавие и Государственная Дума // Голос долга. 1912. № 5. C. 19-21.

Винавер, 1907 - Винавер М.М. Конфликты в первой Думе. СПб., 1907.

Волобуев и др., 1989 - Волобуев О.В., Миллер В.И., Шелохаев В.В. Непролетарские партии России: итоги изучения и нерешенные проблемы // Непролетарские партии России в трех революциях. М., 1989. С. 10-11.

Вортман, 1999 - Вортман $P$. «Официальная народность» и национальный миф российской монархии XIX века // РОССИЯ / RUSSIA. Вып. 3 (11): Культурные практики в идеологической перспективе. М.: ОГИ, 1999. С. 233-244.

Головин, 2006 - Головин Ф.А. Николай II // Николай Второй. Воспоминания. Дневники. М., 2006. C. 11-25.

Голос долга, 1912 - Голос долга. 1912. № 2. С. 6.

Гришин, 2015 - Гришин О.Е. Политическая стабильность: понятие, факторы, инновации // Исторические, философские, политические и юридические науки, культурология и искусствоведение. Вопросы теории и практики. Тамбов: Грамота, 2015. № 6 (56): В 2 ч. Ч. І. С. 51-54.

Гурко, 2000 - Гурко В.И. Черты и силуэты прошлого. Правительство и общественность в царствование Николая II в изображении современника. М., 2000.

Доброхотов, 1907 - Доброхотов А. Ближайшая задача духовенства // Мирный труд. 1907. № 10. C. 65-71.

Езерский, 1907 - Езерский Н.Ф. Государственная дума первого созыва. Пенза, 1907.

За Россию, 1916 - За Россию. 1916. 14 февраля.

Кизеветтер, 2001 - Кизеветтер А.А. На рубеже двух столетий. Воспоминания. 1881-1914. М., 2001.

Киреев, 1907 - Киреев А. Голос старого славянофила // Мирный труд. 1907. № 8-9. С. 223-265.

Кирьяков, 2001 - Кирьяков Ю.И. Правые партии в России. 1911-1917. М., 2001.

Комин, 1965 - Комин В.В. Банкротство буржуазных и мелкобуржуазных партий России в период подготовки и победы Великой Октябрьской социалистической революции. М., 1965. 644 с.

Курицын, 2018 - Курицын А.И. Избирательная программа Союза русского народа на выборах в I и II Государственную Думу // Вестник научной ассоциации студентов и аспирантов исторического факультета Пермского государственного гуманитарно-педагогического университета. Серия «Stadia Historica Jenium». 2018. № 1 (14). C. 83-93. 1906

Львович, 1906 - Львович А. Партии и крестьянство в Государственной думе. Ростов-на-Дону,

Макарычев, 1998 - Макарычев А.С. Стабильность и нестабильность при демократии // Полис. 1998. № 1. C. 149-157. Лавра, 1906

Мышцин, 1906 - Мышцин В.Н. Политические партии и их идеалы. Свято-Троицкая Сергиева

Омельянчук, 2020 - Омельянчук И.В. Социальный аспект идеологии российских консерваторов начала XX столетия // Тетради по консерватизму. 2020. № 1. С. 428-463.

Падение царского режима, 1924 - Падение царского режима: Стенографические отчеты допросов и показаний, данных в 1917 г. чрезвычайной следственной комиссии временного правительства. Л., 1924.

Программы политических партий, 1995 - Программы политических партий России (конец XIX в. - XX в.). М., 1995.

Пуришкевич, 1907 - Пуришкевич B. Накануне (Политические партии в России перед 3-й Думой) // Мирный труд. 1907. № 8-9. С. 12-35.

Спирин, 1968 - Спирин Л.М. Классы и партии в гражданской войне в России. М., 1968.

Спирин, 1977 - Спирин Л.М. Крушение помещичьих и буржуазных партий в России (начало ХХ в. - 1920 г.). М., 1977. 
Устав и Основоположения, 1906 - Устав и Основоположения Союза русского народа. М., 1906.

Ухтубужский, 1912 - Ухтубужский П. Наши идеалы и русская современность // Прямой путь. 1912. № 10. C. 13-15.

Хантингтон, 2004 - Хантингтон С. Политический порядок в меняющихся обществах. М., 2004. C. 58-64.

Швецов, 1907 - Швецов А. Несколько слов о социал-демократах // Мирный труд. 1907. № 10.

Doweling, Kimber, 1983 - Doweling K.M., Kimber R. The Meaning and Use of «Political Stability» // European Journal of Political Research. 1983. Vol. II. № 3. Pp. 28-39.

\section{References}

Arkhiepiskop Nikanor, 1912 - Arkhiepiskop Nikanor. (1912). O vernopoddanicheskikh obyazannostyakh [On loyal duties]. Golos dolga. 5: 4-11 [in Russian]

Berman, 1913 - Berman, Ya. (1913). Vliyanie sotsial'no-pravovogo i ekonomicheskogo faktora na gosudarstvennuyu prestupnost' [Influence of the socio-legal and economic factor on state crime]. Pravo. 33: 1912-1914. [in Russian]

Bogdanovich, 1990 - Bogdanovich, A.V. (1990). Tri poslednikh samoderzhtsa. Dnevnik [The last three autocrat. Diary]. M. [in Russian]

Bokhanov, 2006 - Bokhanov, A.N. (2006). Poslednii tsar' [The Last Tsar]. M. [in Russian]

Dobrokhotov, 1907 - Dobrokhotov, A. (1907). Blizhaishaya zadacha dukhovenstva [The immediate task of the clergy]. Mirnyi trud. 10: 65-71. [in Russian]

Doweling, Kimber, 1983 - Doweling, K.M., Kimber, R. (1983). The Meaning and Use of «Political Stability». European Journal of Political Research. Vol. II. 3: 28-39.

Ezerskii, 1907 - Ezerskii, N.F. (1907). Gosudarstvennaya duma pervogo sozyva [State Duma of the first convocation]. Penza. [in Russian]

Golos dolga, 1912 - Golos dolga. 1912. 2: 6. [in Russian]

Golovin, 2006 - Golovin, F.A. (2006). Nikolai II. Nikolai Vtoroi. Vospominaniya. Dnevniki [Nicholas II]. M. Pp. 11-25. [in Russian]

Grishin, 2015 - Grishin, O.E. (2015). Politicheskaya stabil'nost': ponyatie, faktory, innovatsii. Istoricheskie, filosofskie, politicheskie i yuridicheskie nauki, kul'turologiya i iskusstvovedenie [Political stability: concept, factors, innovation. Historical, philosophical, political and legal sciences, cultural studies and art history. Questions of theory and practice]. Voprosy teorii i praktiki. Tambov: Gramota. 6(56): v 2-kh ch. Ch. I. Pp. 51-54. [in Russian]

Gurko, 2000 - Gurko, V.I. (2000). Cherty i siluety proshlogo. Pravitel'stvo i obshchestvennost' v tsarstvovanie Nikolaya II v izobrazhenii sovremennika [Features and silhouettes of the past. The government and the public in the reign of Nicholas II in the image of a contemporary]. M. [in Russian]

Khantington, 2004 - Khantington, S. (2004). Politicheskii poryadok v menyayushchikhsya obshchestvakh [Political Order in Changing Societies]. M. [in Russian]

Kireev, 1907 - Kireev, A. (1907). Golos starogo slavyanofila [The voice of the old Slavophile]. Mirnyi trud. 8-9: 223-265. [in Russian]

Kir'yakov, 2001 - Kir'yakov, Yu.I. (2001). Pravye partii v Rossii. 1911-1917. M. [in Russian]

[in Russian]

Kizeveter, 2001 - Kizevetter, A.A. (2001). Na rubezhe dvukh stoletii. Vospominaniya. 1881-1914. M.

Komin, 1965 - Komin, V.V. (1965). Bankrotstvo burzhuaznykh i melkoburzhuaznykh partii Rossii v period podgotovki i pobedy Velikoi Oktyabr'skoi sotsialisticheskoi revolyutsii [Bankruptcy of the bourgeois and petty-bourgeois parties of Russia during the preparation and victory of the Great October Socialist Revolution]. M. [in Russian]

Kuritsyn, 2018 - Kuritsyn, A.I. (2018). Izbiratel'naya programma Soyuza russkogo naroda na vyborakh v I i II Gosudarstvennuyu Dumu [The electoral program of the Union of the Russian people in the elections to the I and II State Duma]. Vestnik nauchnoi assotsiatsii studentov $i$ aspirantov istoricheskogo fakul'teta Permskogo gosudarstvennogo gumanitarno-pedagogicheskogo universiteta. Seriya: Stadia Historica Jenium. 1(14): 83-93. [in Russian]

L'vovich, 1906 - L'vovich, A. (1906). Partii i krest'yanstvo v Gosudarstvennoi dume [Parties and the peasantry in the State Duma]. Rostov-na-Donu. [in Russian]

Makarychev, 1998 - Makarychev, A.S. (1998). Stabil'nost' i nestabil'nost' pri demokratii [Stability and instability in democracy]. Polis. 1: 149-157. [in Russian]

Myshtsin, 1906 - Myshtsin, V.N. (1906). Politicheskie partii i ikh idealy. Svyato-Troitskaya Sergieva Lavra [Political parties and their ideals]. Holy Trinity Sergius Lavra. [in Russian]

Omel'yanchuk, 2020 - Omel'yanchuk, I.V. (2020). Sotsial'nyi aspekt ideologii rossiiskikh konservatorov nachala XX stoletiya [The social aspect of the ideology of Russian conservatives at the beginning of the 2oth century]. Tetradi po konservatizmu. 1: 428-463. [in Russian]

Padenie tsarskogo rezhima, 1924 - Padenie tsarskogo rezhima: Stenograficheskie otchety doprosov i pokazanii, dannykh v 1917 g. chrezvychainoi sledstvennoi komissii vremennogo pravitel'stva [The fall of the 
tsarist regime: Verbatim records of interrogations and testimonies given in 1917 by the Extraordinary Commission of Inquiry of the Provisional Government]. L., 1924. [in Russian]

Programmy politicheskikh partii, 1995 - Programmy politicheskikh partii Rossii (konets XIX v. XX v.) [Programs of political parties in Russia (late XIX century - XX century)].M. [in Russian] Purishkevich, 1907 - Purishkevich, V. (1907). Nakanune (Politicheskie partii v Rossii pered 3-i Dumoi)

[On the Eve (Political Parties in Russia before the 3rd Duma)]. Mirnyi trud. 8-9: 12-35. [in Russian] Shvetsov, 1907 - Shvetsov, A. (1907). Neskol'ko slov o sotsial demokratakh [A few words about the social democrats]. Mirnyi trud. 10: 58-64. [in Russian]

Spirin, 1968 - Spirin, L.M. (1968). Klassy i partii v grazhdanskoi voine v Rossii [Classes and Parties in the Civil War in Russia]. M. [in Russian]

Spirin, 1977 - Spirin, L.M. (1977). Krushenie pomeshchich'ikh i burzhuaznykh partii v Rossii (nachalo XX v. - 1920 g.) [The collapse of the landlord and bourgeois parties in Russia (early XX century - 1920)]. M. [in Russian]

Ukhtubuzhskii, 1912 - Ukhtubuzhskii, P. (1912). Nashi idealy i russkaya sovremennost' [Our ideals and Russian modernity]. Pryamoi put'. 10: 13-15. [in Russian]

Ustav i Osnovopolozheniya, 1906 - Ustav i Osnovopolozheniya Soyuza russkogo Naroda [Charter and Foundations of the Union of the Russian People]. M. [in Russian]

Varaksin, 1912 - Varaksin, A. (1912). Tsarskoe samoderzhavie i Gosudarstvennaya Duma [Tsarist autocracy and the State Duma]. Golos dolga. 5: 19-21. [in Russian]

Vinaver, 1907 - Vinaver, M.M. (1907) Konflikty v pervoi Dume [Conflicts in the First Duma]. SPb. [in Russian]

Volobuev i dr., 1989 - Volobuev, O.V., Miller, V.I., Shelokhaev, V.V. (1989). Neproletarskie partii Rossii: itogi izucheniya i nereshennye problem [Non-proletarian parties of Russia: the results of the study and unsolved problems]. Neproletarskie partii Rossii v trekh revolyutsiyakh. M., Pp. 10-11. [in Russian]

Vortman, 1999 - Vortman, R. (1999). "Ofitsial'naya narodnost'» i natsional'nyi mif rossiiskoi monarkhii XIX veka [Political and economic situation of Jews in Russia]. ROSSIYa/RUSSIA. 3(11): Kul'turnye praktiki v ideologicheskoi perspektive. M., Pp. 233-244. [in Russian]

Za Rossiyu, 1916 - Za Rossiyu. 1916. 14 fevralya. [in Russian]

\section{Эволюция воззрений российских монархистов на обеспечение политической стабильности в период 1905-1917 гг.}

Станислав Евгеньевич Прокофьев а, Павел Сергеевич Селезнев a , ${ }^{*}$, Алексей Владимирович Федякин ${ }^{\text {, }}$ Виктор Валериевич Титов а

а Финансовый университет при Правительстве Российской Федерации, Москва, Российская Федерация

b Российский университет транспорта, Москва, Российская Федерация

Аннотация. Данная работа посвящена теме изменения взглядов российских монархистов на стратегию обеспечения стабильности политического и социального режима империи в период 19051917 гг. Целью исследования является выделение основных векторов и трендов в эволюции взглядов монархистов на стратегию обеспечения политической стабильности в Российской империи в обозначенный хронологический отрезок. Источниковая база работы сформирована за счет привлечения материалов дореволюционной периодической печати, источников личного происхождения, публикаций делопроизводственных документов и программных материалов политических партий. Методология работы выстроена на основе комбинирования синхронного и диахронного сравнительного анализа. Сделан вывод о том, что на протяжении рассматриваемого периода взгляды монархистов на стратегию обеспечения политической стабильности империи активно эволюционировали. Первоначально они не имели собственных воззрений по данному вопросу, делегировав функцию определения вектора его решения действующей власти. Однако по мере разрастания революционного кризиса монархисты начали формулировать собственную позицию по вопросу обеспечения стабильности общества. Изначально в их среде популярностью пользовались идеи частичного ограничения полномочий недавно созданных парламентских институтов или реставрации «исконно самодержавных начал» государственного управления. Однако в итоге возобладала точка зрения умеренных монархистов, настаивавших на необходимости создания механизмов, отсекающих политических радикалов от участия в законодательной деятельности. В период 1907-1911 гг. монархисты продвигали идею о том, что необходимо сочетать умеренные реформы с консервацией социальных институтов, обеспечивающих функционирование

\footnotetext{
${ }^{*}$ Корреспондирующий автор

Адреса электронной почты: SEProkofev@fa.ru (С.Е. Прокофьев), PSeleznev@fa.ru (П.С. Селезнев), avf2010@yandex.ru (А.В. Федякин), VVTitov@fa.ru (B.B. Титов)
} 
патриархальной конфигурации российского общества. Также они заостряли внимание на том, что преобразования в социально-экономической сфере должны стать приоритетом для власти: переход к политическим реформам в условиях отсутствия роста уровня жизни населения рассматривался как неоправданный шаг, способный стать катализатором новых революционных потрясений. В дальнейшем монархисты перешли на более радикальные позиции. В условиях начавшейся Первой мировой войны ими активно обсуждались проекты учреждения должности диктатора, объединяющего в своих руках верховные государственно-политические полномочия в гражданской и военной сферах. Таким образом, монархисты вышли за рамки традиционалистской парадигмы самодержавия. Одновременно трансформировалось и само восприятие ими политической стабильности. Первоначально ее рассматривали именно как статичное состояние, соответствующее «священному прошлому». Однако к концу исследуемого периода монархисты интерпретировали стабильность уже как некую адаптивность: сбалансированное, но не константное состояние политической системы, позволяющее государству и обществу сохранять устойчивость к разнообразным внешним и внутренним социальным вызовам за счет поэтапных и последовательных эволюционных преобразований.

Ключевые слова: монархисты, консерваторы, общественно-политическая мысль, политическая стабильность, Российская империя, революция. 